\title{
\&IBRAGEC

\section{ANÁLISE DAS PRINCIPAIS CAUSAS DO NÃO CUMPRIMENTO DE METAS EM EDIFÍCIOS RESIDENCIAIS E COMERCIAIS ${ }^{1}$}

\author{
BARROS, João Victor (1); TAVARES, Ingryd Capistrano Pinto (2); BRANCO, \\ Juliana Quinderé Carneiro Castelo (3); PINHEIRO, Davi Teixeira (4) \\ (1) Instituto Federal do Ceará, jvictorbeng@gmail.com, (2) Instituto Federal do Ceará, \\ ingryd@ifce.edu.br, (3) Faculdade Ari de Sá, juliana@avalengenharia.eng.br, (4) Instituto \\ Federal do Ceará, davi@ifce.edu.br
}

\begin{abstract}
RESUMO
O atraso dos empreendimentos é uma das principais problemáticas do setor da construção civil, a análise de não-conformidades que ocasionam essa problemática, fornece às equipes tendências que podem ser usadas para desenvolver estratégias para evitar a recorrência das mesmas falhas no futuro. Desta forma, esta pesquisa se desenvolve com o intuito de avaliar a aplicação da análise de curto prazo do sistema Last Planner em obras residenciais e comerciais a partir da coleta de um banco de dados de 10 obras verticais de uma torre na construção civil, acompanhadas pela mesma empresa de consultoria em planejamento. Contabilizou-se as cinco causas mais frequentes, sendo a principal delas a mudança no plano de ataque da obra, e utilizando análise estatística observou-se que existe uma grande variabilidade do número de ocorrência das problemáticas ao longo das obras. Além disso, verificou-se que a grande maioria dos problemas são de origens internas, sendo planejamento e mão de obra os dois subgrupos com mais causas do não cumprimento de metas cadastradas. Concluiu-se que analisando as principais causas do não cumprimento das metas de curto prazo e identificando o seu comportamento é possível prever cenários e buscar melhoria contínua do projeto.
\end{abstract}

Palavras chave: Planejamento e Controle de obras, Last Planner System, Lean Construction.

\begin{abstract}
The delay of projects is one of the main problems in the civil construction sector, the analysis of nonconformities that cause this problem provides teams with trends that can be used to develop strategies to avoid the recurrence of the same failures in the future. Thus, this research is developed with the aim of evaluating the application of the short-term analysis of the Last Planner system in residential and commercial works by collecting a database of 10 vertical works of a tower in civil construction, accompanied by same planning consulting firm. The five most frequent causes were counted, the main one being the change in the work's attack plan, and using statistical analysis it was observed that there is a great variability in the number of occurrences of problems throughout the works. In addition, it was found that the vast majority of problems are of internal origins, with planning and labor being the two subgroups with more causes of non-compliance with registered goals. It was concluded that analyzing the main causes of non-compliance with short-term goals and identifying their behavior, it is possible to predict scenarios and seek continuous improvement of the project.
\end{abstract}

Keywords: Causes of not meeting goals, Last Planner System, Lean Construction.

\footnotetext{
1 BARROS, J. V.; TAVARES, I. C. P.; BRANCO, J. Q. C. C.; PINHEIRO, D. T. Análise das principais causas do não cumprimento de metas em edifícios residenciais e comerciais. In: SIMPÓSIO BRASILEIRO DE GESTÃO E ECONOMIA DA CONSTRUÇÃO, 12., 2021, Maceió. Anais[...] Porto Alegre: ANTAC, 2021. p.1-8. Disponível em:

https://eventos.antac.org.br/index.php/sibragec/article/view/556. Acesso em: 2 out. 2021.
} 


\section{INTRODUÇÃO}

No quarto Trimestre do ano de 2020 o setor da construção civil no Brasil apresentou um decréscimo de 7,0\% após um crescimento de 1,5\% em 2019 (CBIC, 2020). Moretti (2015) apresenta que os cenários de crises são propícios para as empresas investirem na redução de suas deficiências, dedicando-se à melhoria de processos.

Entre as principais problemáticas encontradas no setor da construção, destaca-se o atraso na entrega dos empreendimentos. De acordo com Oliveira (2016), 95\% dos empreendimentos no Brasil, são entregues com atraso, este percentual atesta a incapacidade e a falta de planejamento das construtoras.

Um dos problemas ocasionados pelo atraso nas obras são os processos jurídicos, segundo uma pesquisa realizada pela Tapai Advogados (2014), o número de ações contra construtoras no estado de São Paulo passou de 140 processos em 2008 para $3779 \mathrm{em}$ 2013. Entretanto, esse não é o único problema ocasionado por essa problemática, de acordo com Cabrita (2008) os principais efeitos do atraso de obras são: aumento da duração total da obra, aumento do custo total da obra, desentendimentos entre as entidades envolvidas, má imagem imputada ao empreiteiro e aplicação de multas.

De Filippi (2015) afirma que as empresas não atrasam suas obras por existir algum tipo de benefício, e sim por não conseguirem cumprir com o planejado. Diante disso, se faz necessário a identificação das causas dos atrasos. Ballard (2000) afirma que a análise de não-conformidades pode levar às causas principais, sendo necessário a identificação dos motivos pelos quais o trabalho planejado não foi realizado, possibilitando a implementação de melhoria contínua no processo, e consequente melhora no desempenho do projeto.

Resende (2013) afirma que devido ao elevado número de variáveis envolvidas em uma obra, não é fácil apresentar uma solução para todas as problemáticas que ocasionam atraso. Porém, caso seja efetuado uma identificação e compreensão das causas, consequências e medidas de prevenção praticadas, poderá ser possível fornecer ajudas e contribuições na minimização de atrasos e contribuir para a melhoria da gestão e produtividade das empresas.

Diante do exposto, como forma de contribuir com a problemática apresentada, este trabalho tem como objetivo analisar um banco de dados de uma empresa de consultoria em planejamento de 10 obras verticais identificando quais são as problemáticas mais recorrentes que ocasionam o não cumprimento de metas do planejamento de curto prazo. Como resultado, espera-se que a pesquisa colabore com o desenvolvimento de ações mitigadoras para combater as principais causas encontradas.

\section{METODOLOGIA}

Esta pesquisa foi desenvolvida a partir da análise de dados oriundos da aplicação do Sistema Last Planner. As informações foram disponibilizadas por uma empresa de consultoria e gerenciamento de obras, isto é, o estudo dispôs de um banco de dados disponível para ser analisado.

Desta forma, esse estudo é classificado como sendo uma Pesquisa Documental. De acordo com Pimentel (2001) este tipo de pesquisa extrai dos arquivos toda a análise, organizando-os e interpretando-os segundo os objetivos da investigação proposta.

O estudo contemplou dados coletados entre os anos de 2014 e 2020 de 7 empresas distribuídos em 10 empreendimentos de concreto armado, compostos de uma única torre localizados nas regiões Nordeste e Sul. O Quadro 1 apresenta as características dos empreendimentos analisados. 
Quadro 1 - Descrição dos empreendimentos

\begin{tabular}{|l|l|l|l|l|l|}
\hline Obra & Construtora & $\begin{array}{l}\text { Área } \\
\text { Construída }\left(\mathbf{m}^{2}\right)\end{array}$ & $\begin{array}{l}\text { Orçamento } \\
\text { Base } \mathbf{( R \$ )}\end{array}$ & Tipologia & Cidade \\
\hline 1 & A & $38.595,98$ & $54.045 .269,53$ & Comercial & Campina Grande \\
\hline 2 & A & $19.985,22$ & $22.853 .343,38$ & Residencial & Campina Grande \\
\hline 3 & B & $5.599,08$ & $8.753 .339,89$ & Residencial & Sobral \\
\hline 4 & C & $2.060,53$ & $36.329 .762,64$ & Comercial & Florianópolis \\
\hline 5 & D & $14.090,27$ & $27.227 .904,41$ & Residencial & Fortaleza \\
\hline 6 & E & $12.547,53$ & $20.923 .241,58$ & Residencial & Campina Grande \\
\hline 7 & F & $15.816,63$ & $24.361 .821,71$ & Residencial & Fortaleza \\
\hline 8 & F & $17.486,20$ & $26.685 .614,88$ & Residencial & Fortaleza \\
\hline 9 & F & 13429,00 & 22715742,53 & Residencial & Fortaleza \\
\hline 10 & G & 15731,74 & 23353371,2 & Residencial & Fortaleza \\
\hline
\end{tabular}

Fonte: Elaborado pelos autores (2021).

A primeira etapa do trabalho foi a triagem dos dados, a partir de um banco de dados de 20 obras, foram escolhidas aquelas que possuíam mais de $70 \%$ dos meses com as causas do não cumprimento de metas cadastradas no sistema. Posteriormente, foi realizada a coleta de dados, o objetivo maior do levantamento de dados é obter as causas do não cumprimento de metas, as informações presentes nesse relatório foram obtidas a partir do envio de uma lista de atividades, que estavam previstas serem realizadas no período e não foram, para ser justificado o motivo do não cumprimento dessas metas. No preenchimento desse questionário o cliente possui algumas possibilidades de respostas e escolhe aquela que melhor justifica a não realização de determinada atividade.

Estas informações, referente a cada obra, foram captadas mês a mês. Após a coleta de informações, houve uma organização e unificação de todos os relatórios por obra em uma planilha eletrônica, por meio da ferramenta Microsoft Office Excel, com o intuito de facilitar análises futuras.

Na última etapa, os dados foram analisados pelas seguintes perspectivas:

i. Ocorrências do não cumprimento de metas;

ii. $\quad$ Tendência central e dispersão;

iii. Causas em grupos e subgrupos;

A primeira análise realizada foi individual para cada obra utilizando o processo de contagem do número de ocorrências, resultando na identificação das principais causas de cada obra e o percentual de cada problema em relação ao número total desses na obra. Após a análise individual, foi realizado o procedimento similar para o conjunto dos 10 empreendimentos analisados, somando a quantidade de cada problema por obra e encontrado os valores globais.

Logo após, a estatística descritiva foi utilizada na caracterização das tendências centrais e de dispersão dos dados de percentual de ocorrência dos problemas nas obras. Como o número total de ocorrência cadastradas nas obras modificam bastante, essa análise informa se as principais causas encontradas pelo processo de contagem têm o grau de importância alto em todas as obras analisadas. Desta forma, foram utilizados os percentuais de ocorrências das cinco principais causas em cada obra para as análises.

Por fim, as causas do não cumprimento de metas foram divididas em grupos e subgrupos, adotando-se a classificação utilizada por Bortolazza (2006). Os grupos são divididos em problemas internos da construtora (mão-de-obra, materiais, equipamento, projeto e planejamento), e os problemas externos (interferência do cliente, problemas meteorológicos e fornecedores). Após a divisão realizou-se os cálculos dos percentuais médios dos grupos e subgrupos. 


\section{RESULTADOS E DISCUSSÕES}

\subsection{Ocorrência do não cumprimento de metas}

Foi realizado um processo de contagem das causas do não cumprimento de metas. Ao todo foram cadastradas 12.226 causas para o não cumprimento das metas, dividindo-se entre 37 motivos distintos, definidos pela análise da empresa de consultoria, algumas opções de respostas, não tiveram nenhuma causa cadastrada. A Figura 1 apresenta o percentual de ocorrência das dez principais causas do não cumprimento de metas.

Figura 1 - Dez principais causas do não cumprimento de metas na avaliação geral de contagem

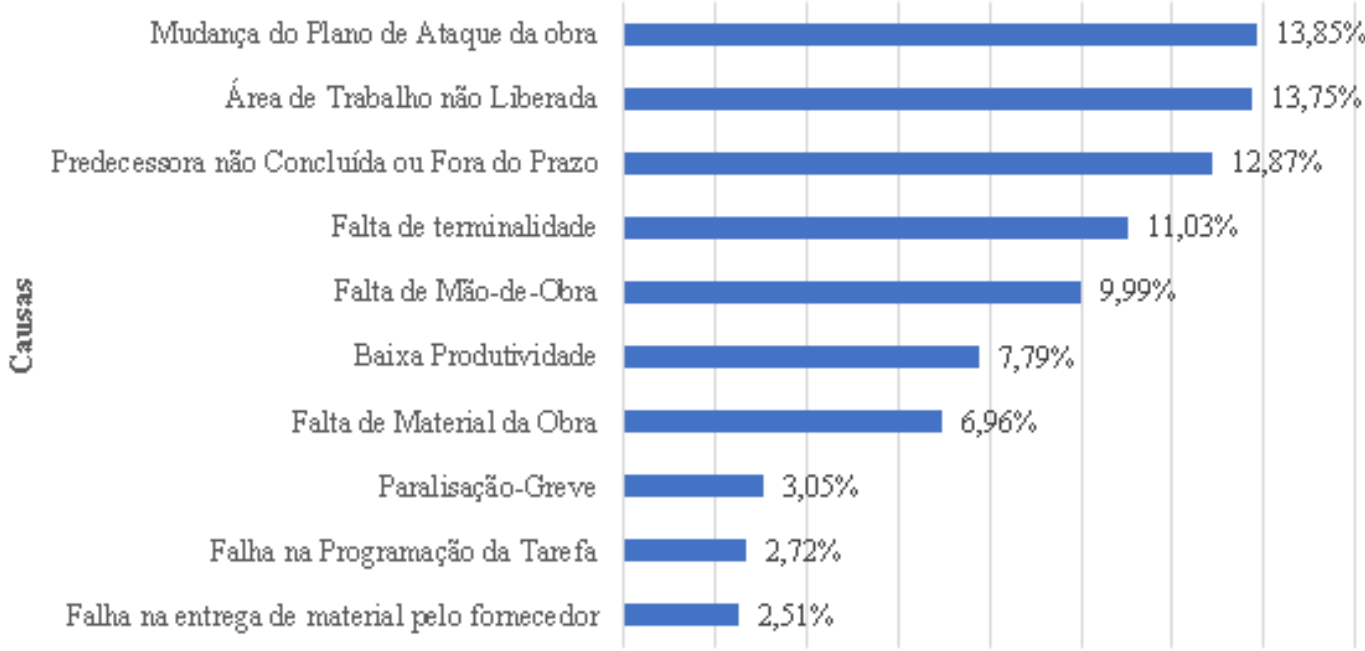

$0,00 \% 2,00 \% 4,00 \% 6,00 \% 8,00 \%, 10,00 \% 12,00 \% 14,00 \% 16,00 \%$

\% ocorrência

Fonte: Elaborado pelos autores (2021).

Constatou-se que a principal problemática é a mudança do plano de ataque da obra, o plano de ataque é o ato de elaborar um roteiro de atividades a ser seguido para realização de um empreendimento. As imprevisibilidades presentes em um canteiro de obra, faz com que as mudanças no plano de ataque da obra aconteçam com elevada frequência. $\mathrm{O}$ surgimento de atividades não previstas, priorização de execução em outro local ou mudança da sequência construtiva ocasionam essas modificações. O Quadro 2 apresenta as cinco principais causas encontradas para os 10 empreendimentos analisados.

Quadro 2 - Cinco Principais causas do não cumprimento de metas dos empreendimentos

\begin{tabular}{|c|c|c|c|c|c|}
\hline Obra & Primeira & Segunda & Terceira & Quarta & Quinta \\
\hline 1 & $\begin{array}{l}\text { Mudança do Plano de } \\
\text { Ataque da obra }\end{array}$ & $\begin{array}{l}\text { Predecessora não } \\
\text { Concluída ou } \\
\text { Fora do Prazo }\end{array}$ & $\begin{array}{l}\text { Projeto } \\
\text { Deficiente ou } \\
\text { Inexistente } \\
\end{array}$ & $\begin{array}{l}\text { Área de } \\
\text { Trabalho não } \\
\text { Liberada } \\
\end{array}$ & $\begin{array}{l}\text { Falta de Definição } \\
\text { Opção do } \\
\text { Cliente/Comercial }\end{array}$ \\
\hline 2 & $\begin{array}{l}\text { Mudança do Plano de } \\
\text { Ataque da obra }\end{array}$ & $\begin{array}{l}\text { Falta de mão de } \\
\text { obra }\end{array}$ & $\begin{array}{l}\text { Modificação } \\
\text { de Projeto }\end{array}$ & $\begin{array}{l}\text { Pacote de } \\
\text { Trabalho } \\
\text { Grande } \\
\text { Demais }\end{array}$ & $\begin{array}{l}\text { Falha na } \\
\text { Programação da } \\
\text { Tarefa }\end{array}$ \\
\hline 3 & Falta de terminalidade & Outros & $\begin{array}{l}\text { Falha na } \\
\text { Programação } \\
\text { da Tarefa } \\
\end{array}$ & \begin{tabular}{|l} 
Área de \\
Trabalho não \\
Liberada \\
\end{tabular} & $\begin{array}{l}\text { Predecessora não } \\
\text { Concluída ou Fora } \\
\text { do Prazo }\end{array}$ \\
\hline 4 & $\begin{array}{l}\text { Mudança do Plano de } \\
\text { Ataque da obra }\end{array}$ & Chuva & $\begin{array}{l}\text { Predecessora } \\
\text { não } \\
\text { Concluída ou } \\
\text { Fora do Prazo }\end{array}$ & \begin{tabular}{|l|} 
Baixa \\
Produtividade
\end{tabular} & $\begin{array}{l}\text { Rescisão } \\
\text { Contratual do } \\
\text { Empreiteiro }\end{array}$ \\
\hline
\end{tabular}




\begin{tabular}{|c|c|c|c|c|c|}
\hline 5 & $\begin{array}{l}\text { Falta de Definição } \\
\text { Opção do } \\
\text { Cliente/Comercial }\end{array}$ & $\begin{array}{l}\text { Predecessora não } \\
\text { Concluída ou } \\
\text { Fora do Prazo }\end{array}$ & $\begin{array}{l}\text { Mudança do } \\
\text { Plano de } \\
\text { Ataque da } \\
\text { obra }\end{array}$ & $\begin{array}{l}\text { Falta de Mão- } \\
\text { de-Obra }\end{array}$ & $\begin{array}{l}\text { Baixa } \\
\text { Produtividade }\end{array}$ \\
\hline 6 & $\begin{array}{l}\text { Predecessora não } \\
\text { Concluída ou Fora do } \\
\text { Prazo }\end{array}$ & $\begin{array}{l}\text { Falha na entrega } \\
\text { de material pelo } \\
\text { fornecedor }\end{array}$ & $\begin{array}{l}\text { Falta de Mão } \\
\text { de Obra }\end{array}$ & $\begin{array}{l}\text { Mudança do } \\
\text { Plano de } \\
\text { Ataque da } \\
\text { obra }\end{array}$ & $\begin{array}{l}\text { Baixa } \\
\text { Produtividade }\end{array}$ \\
\hline 7 & $\begin{array}{l}\text { Predecessora não } \\
\text { Concluída ou Fora do } \\
\text { Prazo }\end{array}$ & $\begin{array}{l}\text { Falta de Mão de } \\
\text { Obra }\end{array}$ & $\begin{array}{l}\text { Área de } \\
\text { Trabalho não } \\
\text { Liberada }\end{array}$ & $\begin{array}{l}\text { Mudança do } \\
\text { Plano de } \\
\text { Ataque da } \\
\text { obra }\end{array}$ & $\begin{array}{l}\text { Baixa } \\
\text { Produtividade }\end{array}$ \\
\hline 8 & $\begin{array}{l}\text { Área de Trabalho não } \\
\text { Liberada }\end{array}$ & $\begin{array}{l}\text { Falta de } \\
\text { terminalidade }\end{array}$ & $\begin{array}{l}\text { Modificação } \\
\text { de Projeto }\end{array}$ & $\begin{array}{l}\text { Paralisação- } \\
\text { Greve }\end{array}$ & $\begin{array}{l}\text { Mudança do Plano } \\
\text { de Ataque da obra }\end{array}$ \\
\hline 9 & $\begin{array}{l}\text { Área de Trabalho não } \\
\text { Liberada }\end{array}$ & $\begin{array}{l}\text { Predecessora não } \\
\text { Concluída ou } \\
\text { Fora do Prazo }\end{array}$ & $\begin{array}{l}\text { Falta de Mão } \\
\text { de Obra }\end{array}$ & $\begin{array}{l}\text { Mudança do } \\
\text { Plano de } \\
\text { Ataque da } \\
\text { obra }\end{array}$ & $\begin{array}{l}\text { Falta de Material } \\
\text { da Obra }\end{array}$ \\
\hline 10 & $\begin{array}{l}\text { Predecessora não } \\
\text { Concluída ou Fora do } \\
\text { Prazo }\end{array}$ & $\begin{array}{l}\text { Falta de } \\
\text { terminalidade }\end{array}$ & $\begin{array}{l}\text { Baixa } \\
\text { Produtividade }\end{array}$ & $\begin{array}{l}\text { Falta de } \\
\text { Material da } \\
\text { Obra }\end{array}$ & $\begin{array}{l}\text { Falta de Mão de } \\
\text { Obra }\end{array}$ \\
\hline
\end{tabular}

Fonte: Elaborado pelos autores (2021).

Observa-se que para os dez empreendimentos analisados, foram apresentadas cinco causas principais distintas. Mudança do plano de ataque da obra e Predecessora não concluída ou fora do prazo, lideram como principal problemática em três obras cada uma, seguida por Área de trabalho não liberada que possui o maior número de ocorrência em duas obras. Por fim, Falta de terminalidade e Falta de definição opção do cliente/comercial são as principais problemáticas em uma obra cada.

\subsection{Tendencia Central e Dispersão}

Foram realizadas análises estatísticas para avaliar a tendência central e dispersão das cinco principais causas encontradas no processo de contagem. Os valores do percentual de ocorrência dessas causas em cada obra serviram como base para essa análise. Primeiramente, foi calculado em cada obra o percentual de ocorrência de cada problemática, dividindo a sua quantidade de ocorrência pelo número total de causas cadastradas no empreendimento. Logo após, de posse dos percentuais de ocorrências das cinco principais causas em cada obra, calculou-se a tendência e dispersão de cada problemática ao longo das obras. O Quadro 3 demonstra os valores de tendência central, por meio da média e mediana, e dispersão a partir dos valores de desvio padrão e coeficiente de variação para as cinco principais causas.

Quadro 3 - Tendências centrais e dispersão das cinco principais causas

\begin{tabular}{|l|l|l|l|l|}
\hline & Média $(\boldsymbol{\%})$ & $\begin{array}{l}\text { Mediana } \\
(\mathbf{\%})\end{array}$ & $\begin{array}{l}\text { Desvio padrão } \\
(\boldsymbol{\%})\end{array}$ & $\begin{array}{l}\text { Coeficiente de } \\
\text { Variação }(\%)\end{array}$ \\
\hline $\begin{array}{l}\text { Mudança do plano de ataque } \\
\text { da obra }\end{array}$ & 16,96 & 12,01 & 15,75 & 93 \\
\hline Área de trabalho não liberada & 10,39 & 8,34 & 10,75 & 103 \\
\hline $\begin{array}{l}\text { Predecessora não concluída } \\
\text { ou fora do prazo }\end{array}$ & 12,69 & 14,44 & 6,25 & 49 \\
\hline Falta de terminalidade & 9,99 & 1,76 & 14,50 & 145 \\
\hline Falta de Mão de obra & 10,16 & 11,04 & 6,67 & 66 \\
\hline
\end{tabular}

Fonte: Elaborado pelos autores (2021).

Os valores apresentados no Quadro 3 de tendências centrais para as cinco principais causas, analisando individualmente cada obra, indicam valores médios elevados para as 
problemáticas avaliadas. Porém, na mesma tabela é possível verificar que existem valores elevados de discrepância, o que torna a média um parâmetro menos assertivo.

A Figura 2 mostra a variação dos valores de percentual de causas por meio de um diagrama de caixa ou Boxplot. Este gráfico permite avaliar a variação numérica por meio de quartis, além dos quartis também é possível verificar os limites superiores e inferiores e os outliers ou pontos discrepantes.

Figura 2 - Gráfico Boxplot da variação numérica dos percentuais de causas por obra

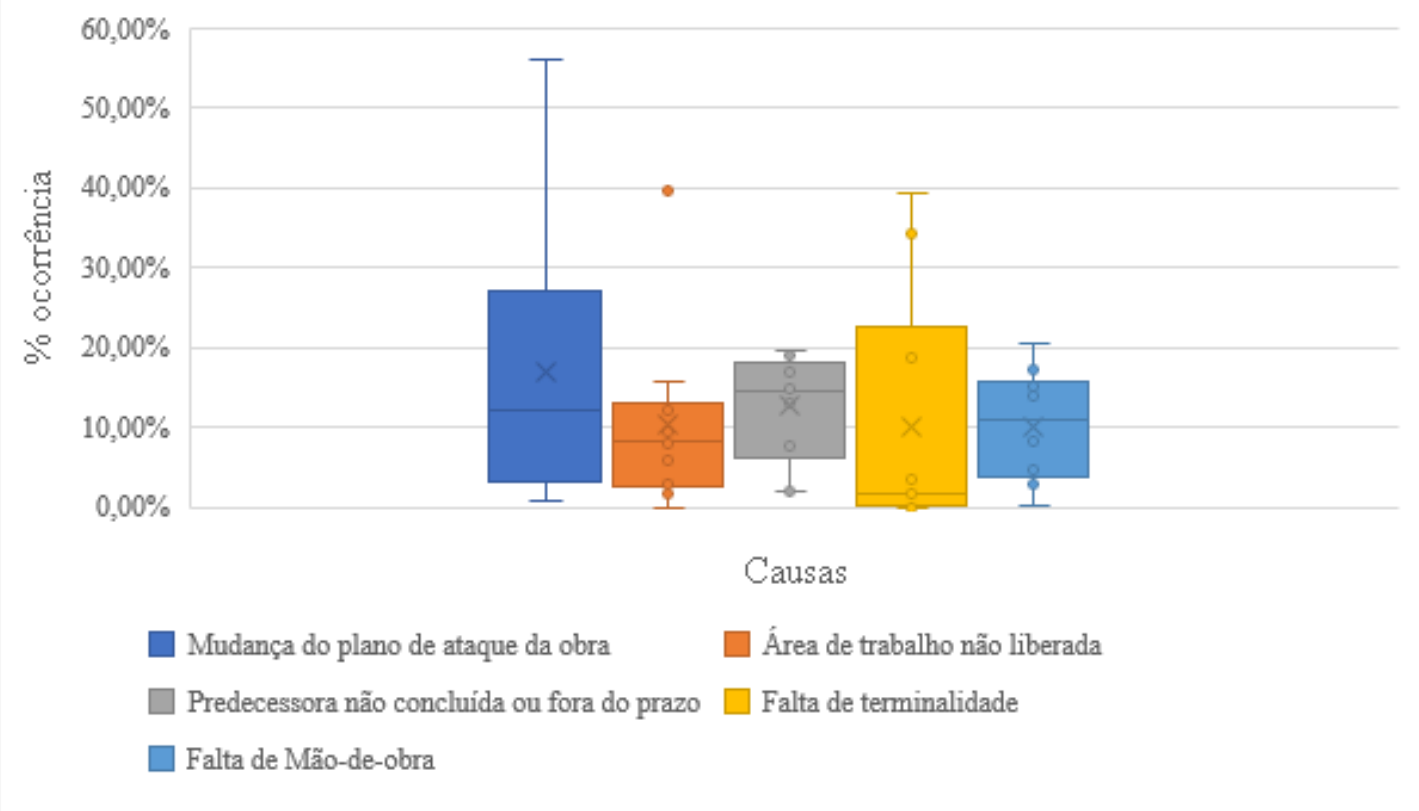

Fonte: Elaborado pelos autores (2021).

De acordo com o gráfico apresentado, é possível constatar a alta variação da problemática mudança do plano de ataque da obra, tendo como o seu limite superior o percentual de $56 \%$ das ocorrências. Também é possível verificar a pequena variação da problemática área de trabalho não liberada. Além disso, pode-se observar a existência de pontos discrepantes em todas as outras causas avaliadas, indicando assim um alto grau de importância em determinadas obras.

\subsection{Causas por grupo e subgrupos}

As possibilidades de causas disponibilizadas pela empresa de gerenciamento aos seus clientes, foram agrupadas de acordo com a classificação sugerida por Bortolazza (2006). Logo após, calculou-se a relação da contagem de problemática de cada grupo com o número total de causas cadastradas. O Quadro 2 apresenta o percentual de causas ocasionadas por motivos internos e externos da construtora.

Quadro 2 - Distribuição das causas do não cumprimento de metas por grupos

\begin{tabular}{|l|l|}
\hline Origem & Percentual (\%) \\
\hline Interna & 92 \\
\hline Externa & 7 \\
\hline Outras & 2 \\
\hline
\end{tabular}

Fonte: Elaborado pelos autores (2021)

Os dados apresentados confirmam a predominância dos problemas de origens internas, confirmando a possibilidade de melhora do processo de planejamento e controle da produção das construtoras. O mesmo procedimento realizado para os grupos foi realizado para os subgrupos. A Figura 3 apresenta os percentuais médios dos subgrupos proposto por Bortolazza (2006). 


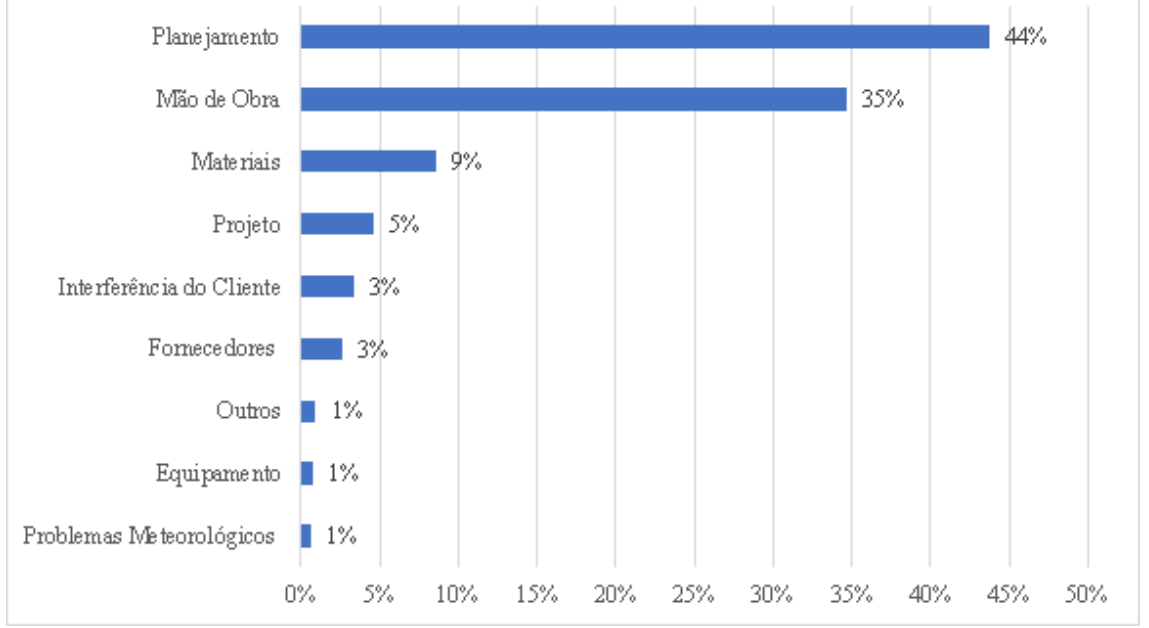

Fonte: Elaborado pelos autores (2021).

Os dois grupos com maior número de ocorrências no trabalho de Bortolazza (2006) foram Mão de obra (35\%) e Planejamento (30\%). Estes subgrupos mantiveram-se entre os principais, modificando apenas a ordem entre eles Planejamento (44\%) e Mão de obra (35\%). A Figura 4 compara os resultados obtidos nesta pesquisa com os trabalhos de Bortolazza (2006) e Moura (2008).

Figura 4 - Comparação dos resultados obtidos

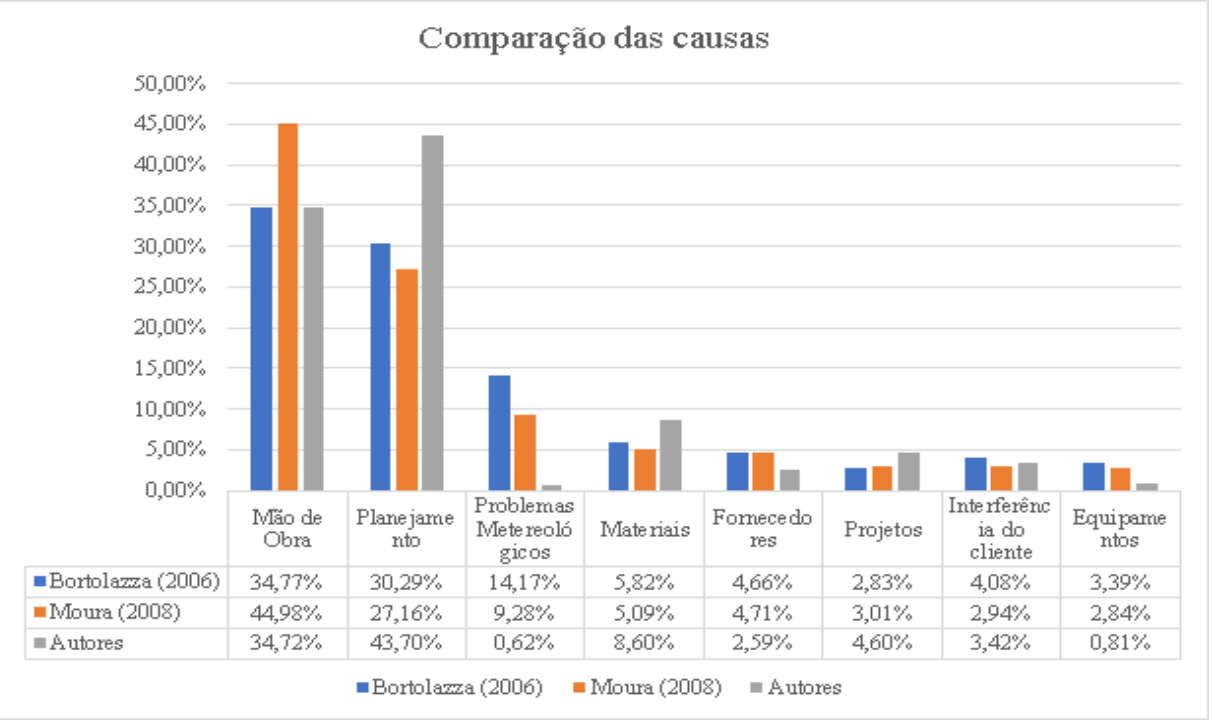

Fonte: Elaborado pelos autores (2021).

\section{CONSIDERAÇÕES FINAIS}

Durante a realização da pesquisa foi possível identificar os principais problemas encontrados pelas obras analisadas. Sendo eles, mudança do plano de ataque da obra, área de trabalho não liberada, predecessora não concluída ou fora do prazo, falta de terminalidade e falta de mão de obra. Sendo possível então, auxiliar os gestores de obras no processo de tomada de decisão e na implementação de processos de melhoria contínua.

Além disso, com a utilização da estatística descritiva foi possível verificar que a média do percentual de ocorrência de cada problema ao longo das obras se manteve elevado. Contudo, as amostras tiveram um elevado valor de desvio padrão, caracterizando que o nível de relevância dos problemas varia de acordo com as obras.

A outra análise realizada foi dos grupos e subgrupos, constatou que os principais problemas são de origem internas, possibilitando assim a melhoria nos processos internos 
da construtora, os subgrupos com mais causas cadastradas são planejamento e mão de obra, valor similar ao apresentado nos trabalhos de Bortolazza (2006) e Moura (2008), evidenciando a continuidade das problemáticas referente a esses dois grupos no setor da construção civil.

Por fim, essa pesquisa contribuiu com o avanço nos assuntos relacionados a planejamento e controle de obras, tanto no aspecto acadêmico como prático. Além disso, auxilia no processo de implementação de melhoria contínua nas obras.

\section{REFERÊNCIAS}

BALLARD, G The last planner system of production control. 2000. 193f. Thesis (Doctor of Philosophy) - School of Civil Engineering, Faculty of Engineering. University of Birmingham, Birmingham.

BORTOLAZZA, R. C. Contribuições para a coleta e a análise de indicadores de planejamento e controle da produção na construção civil. 2006. 178f. Tese (Mestrado em Engenharia) - Universidade Federal do Rio Grande do Sul, Rio Grande do Sul.

CBIC. PIB Brasil e Construção Civil. [banco de dados]: Câmara Brasileira da Indústria da Construção, 2020.

CABRITA, A. F. Atrasos na Construção: Causas, Efeitos E Medidas De Mitigação. 2008. 177f. Dissertação (Mestrado em Engenharia Civil) - Instituto Superior de Ensino, Lisboa, Portugal, 2008.

DE FILIPPI, G. A.; MELHADO, S. B. Um Estudo Sobre as Causas de Atrasos de Obras de Empreendimentos Imobiliários na Região Metropolitana de São Paulo. Ambiente Construído, Porto Alegre, v. 15, n. 3, p. 161-173, jul./set. 2015.

MOURA, C. B. Avaliação do impacto do Sistema Last Planner no desempenho de empreendimentos da construção civil. 2008. 170f. Dissertação Mestrado (Mestrado em Engenharia Civil) - Universidade Federal do Rio Grande do Sul, 2008.

Moretti, C. E. Crise: o momento ideal para a implantação do lean. Jun. 2015.

Disponível em: <http://vanzolini.org.br/blog/2015/06/crise-o-momento-ideal-para-aimplantacao-do-lean>. Acesso em: 22 abr. 2021.

OLIVEIRA, S. B. 95\% dos empreendimentos imobiliários são entregues com atrasos no Brasil. Entendam os seus direitos!. 2006 Disponível em< https://jus.com.br/artigos/52349/95-dos-empreendimentos-imobiliarios-sao-entreguescom-atrasos-no-brasil-entendam-os-seus-direitos>. Acesso em: 03 maio 2021.

PIMENTEL, A. O método da análise documental: seu uso numa pesquisa historiográfica. Cadernos de Pesquisa, n.114, p. 179-195, 2001.

RESENDE, C.C.R. Atrasos de obra devido a problemas no Gerenciamento. 2013. 61f. Monografia (Graduação em Engenharia Civil) - Universidade Federal do Rio de Janeiro, Rio de Janeiro.

Tapai Advogados. Ações Contra Construtoras Disparam 2600\% nos Últimos Cinco Anos. 2014 Disponível em<

http://www.tapaiadvogados.com.br/imprensa >. Acesso em: 07 maio 2021. 